NRE L National Renewable Energy Laboratory

A New Empirical Relationship between Thrust Coefficient and Induction Factor for the Turbulent Windmill State

Marshall L. Buhl, Jr.

Technical Report NREL/TP-500-36834 August 2005

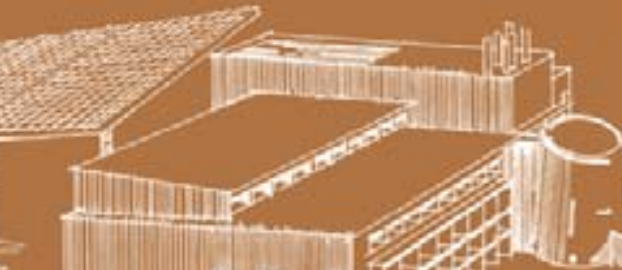




\section{A New Empirical Relationship between Thrust Coefficient and Induction Factor for the Turbulent Windmill State}

Marshall L. Buhl, Jr.

Prepared under Task No(s). WER5.3316

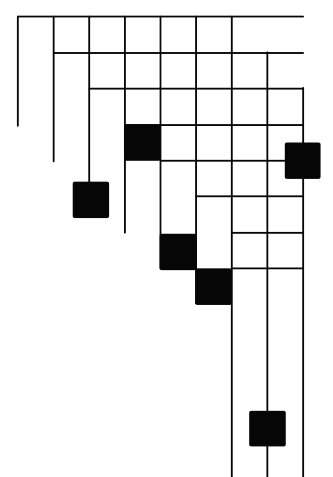




\section{NOTICE}

This report was prepared as an account of work sponsored by an agency of the United States government. Neither the United States government nor any agency thereof, nor any of their employees, makes any warranty, express or implied, or assumes any legal liability or responsibility for the accuracy, completeness, or usefulness of any information, apparatus, product, or process disclosed, or represents that its use would not infringe privately owned rights. Reference herein to any specific commercial product, process, or service by trade name, trademark, manufacturer, or otherwise does not necessarily constitute or imply its endorsement, recommendation, or favoring by the United States government or any agency thereof. The views and opinions of authors expressed herein do not necessarily state or reflect those of the United States government or any agency thereof.

Available electronically at http://www.osti.gov/bridge

Available for a processing fee to U.S. Department of Energy and its contractors, in paper, from:

U.S. Department of Energy

Office of Scientific and Technical Information

P.O. Box 62

Oak Ridge, TN 37831-0062

phone: 865.576 .8401

fax: 865.576 .5728

email: mailto:reports@adonis.osti.gov

Available for sale to the public, in paper, from:

U.S. Department of Commerce

National Technical Information Service

5285 Port Royal Road

Springfield, VA 22161

phone: 800.553.6847

fax: 703.605.6900

email: orders@ntis.fedworld.gov

online ordering: http://www.ntis.gov/ordering.htm 


\section{Contents}

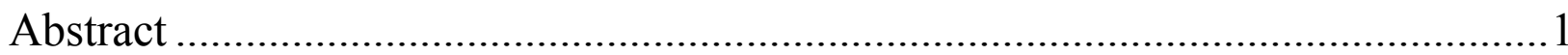

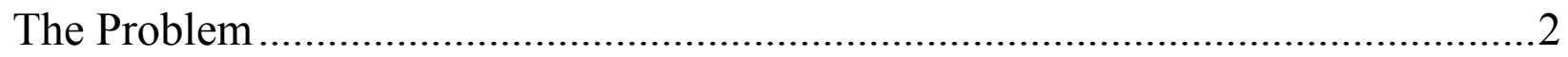

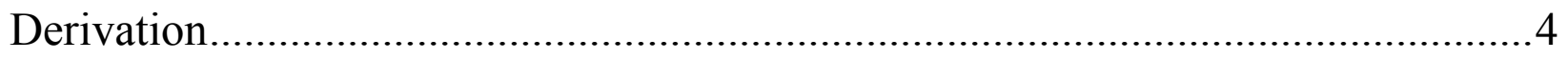

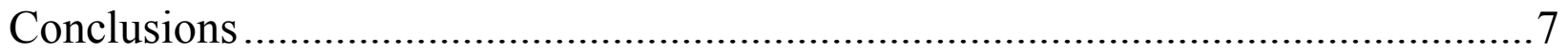

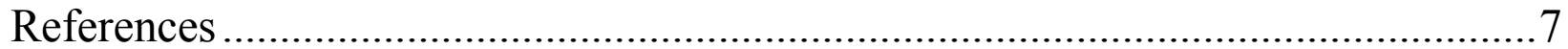

\section{Figures}

Figure 1. Classical $\mathrm{C}_{\mathrm{r}}-$ a curve when losses are ignored ..................................

Figure 2. Classical $C_{r}$ a curve and Glauert's empirical relationship

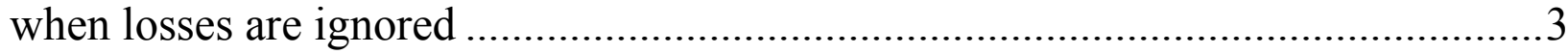

Figure 3. Classical $\mathrm{C}_{\mathrm{r}}-$ a curve with losses $(F=0.9)$ included and Glauert's empirical relationship

Figure 4. Classical $\mathrm{C}_{\mathrm{r}}$ - a curve and Glauert's empirical relationship when losses $(F=0.9)$ are included in both equations 5

Figure 5. Classical $\mathrm{C}_{\mathrm{r}}-$ a curve and the newly derived empirical relationship when losses $(F=0.9)$ are included in both equations 6 


\begin{abstract}
Wind turbines sometimes experience the turbulent windmill state during startup or shutdown. This rarely happens during normal operation, so it has little effect on power curves or energy production. However, for completeness we need to be able to model situations where the axial induction factor exceeds 0.5 . Classical momentum theory, which shows a relationship between the thrust coefficient and the axial induction factor, is not valid in this region. Glauert plotted some experimental data taken by Lock in the 1920s against this parabolic relationship and found very poor agreement for operation in this high-induction state. He proposed a new empirical relationship to fit the experimental data. Unfortunately, the new empirical curve does not account for tip or hub losses. Others have proposed multiplying the axial induction factor by the loss factor to correct the curve, but this still leaves a mathematical no-man's-land between the classical curve and the modified version of Glauert's empirical curve. The purpose of this paper is to document the derivation of a new curve that accounts for tip and hub losses and eliminates the numerical problems of the previous approaches.
\end{abstract}




\section{The Problem}

A review of several textbooks on wind turbine theory revealed that no one has addressed the numerical discontinuity problem associated with the Glauert empirical relationship (Lock et al. [1926], Glauert [1926]) between thrust coefficient and axial induction when tip losses are applied to the turbulent windmill state. (See Burton et al. [2001], Eggleston and Stoddard [1987], Manwell et al. [2002], and Spera [1994] for discussions of classical momentum theory and the Glauert empirical equation.) Eggleston and Stoddard discussed the classical thrust coefficient, $C_{T}$, versus induction factor, $a$, curve, which is shown in Equation 1 and Figure 1. The dotted portion of the curve above the induction value of 0.5 represents the portion of the curve that violates the basic assumptions used to derive it.

$$
C_{T}=4 a(1-a)
$$

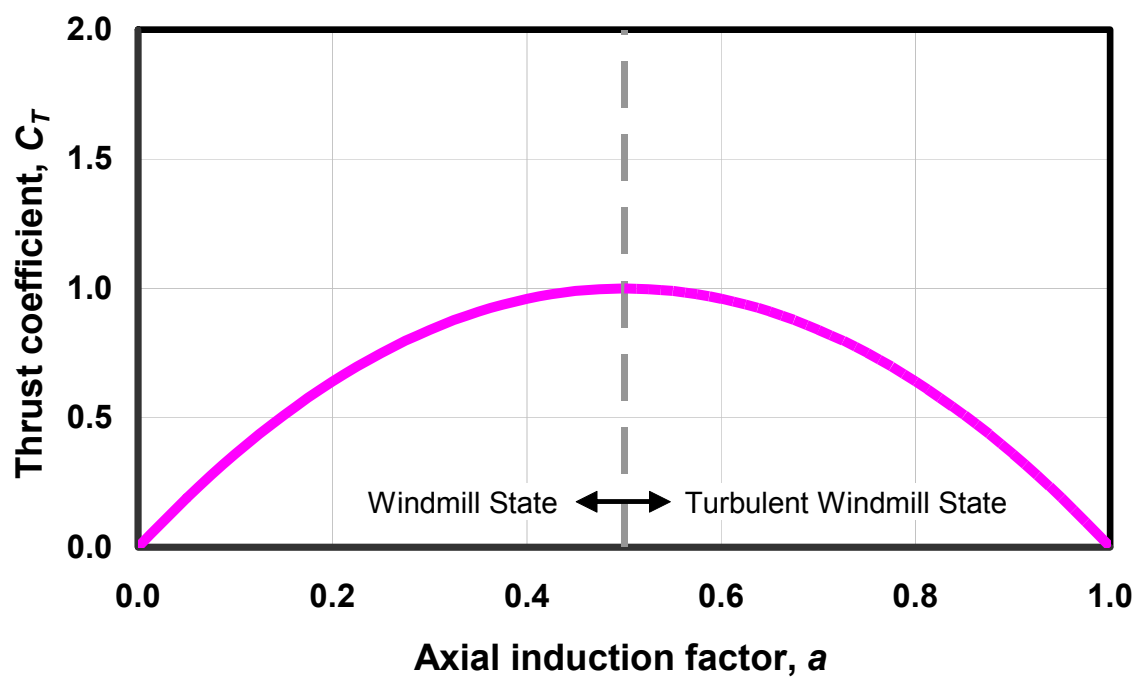

Figure 1. Classical $C_{T}-$ a curve when losses are ignored

Glauert fit a parabola to some experimental data of rotors operating in the turbulent windmill state. This parabola touched the classical momentum curve at $a=0.4$ and went through 2.0 for $a$ $=1.0$. The curve, as documented by Eggleston and Stoddard, is given by the formula shown in Equation 2 after solving for $C_{T}$. Burton et al. used a line that is tangential to the theory parabola to fit the data. The choice of the intersection determines the slope and fit of the curve. The Burton textbook proposed an induction value of 0.326 for the intersection of the two curves. The book also reported that Wilson and Lissaman chose a value of 0.368 . A plot of the three empirical curves with the classical momentum theory curve and the test data is shown in Figure 2. We digitized the test data from Figure 3.16 of Burton's book. There is a large spread in the data, which indicates that the thrust coefficient is not a simple function of induction factor in the turbulent windmill state.

$$
C_{T}=0.889-\frac{0.0203-(a-0.143)^{2}}{0.6427}
$$




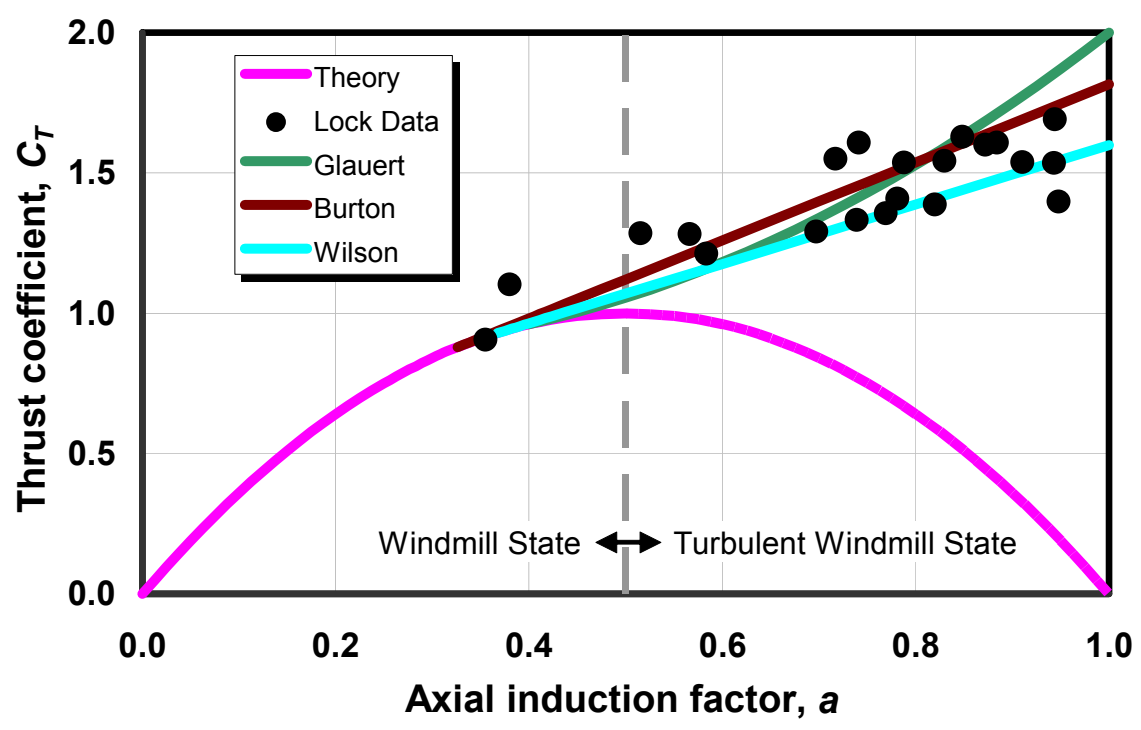

Figure 2. Classical $C_{T}-$ a curve and Glauert's empirical relationship when losses are ignored

A numerical problem arises when one applies the tip/hub loss correction factor, $F$, to the classical momentum balance equation (see Equation 3).

$$
C_{T}=4 a F(1-a)
$$

Plotting this modified equation shows a gap between the momentum curve and Glauert's curve (Figure 3) for a loss factor of 0.9 . This gap creates a discontinuity when a computer is used to iterate for the induction factor. Eggleston and Stoddard modified Equation 2 to multiply the induction factor by the loss factor. This modification to the Glauert empirical relationship lowers the entire curve, but not enough to eliminate all of the discontinuity (see Figure 4). 


\section{Derivation}

For the turbulent windmill state we need a curve that tangentially touches the classical momentum curve and thereby eliminates the numerical no-man's-land. The data Glauert used exhibit a very wide scatter. The resulting equation was probably chosen to resolve the numerical problem rather than to obtain a good fit for the data. (See Eggleston and Stoddard, p. 22 for a plot of the data.) Therefore, choosing a parabolic curve that has the same value and slope for $a=0.4$ as the classical equation with losses, and that goes through 2.0 at $a=1.0$, should be somewhat reasonable. We can do this with simple algebra.

The derivative of Equation 1 (assuming fixed $\mathrm{F}$ for a given iteration) gives

$$
\frac{d C_{T}}{d a}=4 F(1-2 a) .
$$

At $\mathrm{a}=0.4$, Equations 3 and 4 become

$$
C_{T}=0.96 F
$$

and

$$
\frac{d C_{T}}{d a}=0.8 F .
$$

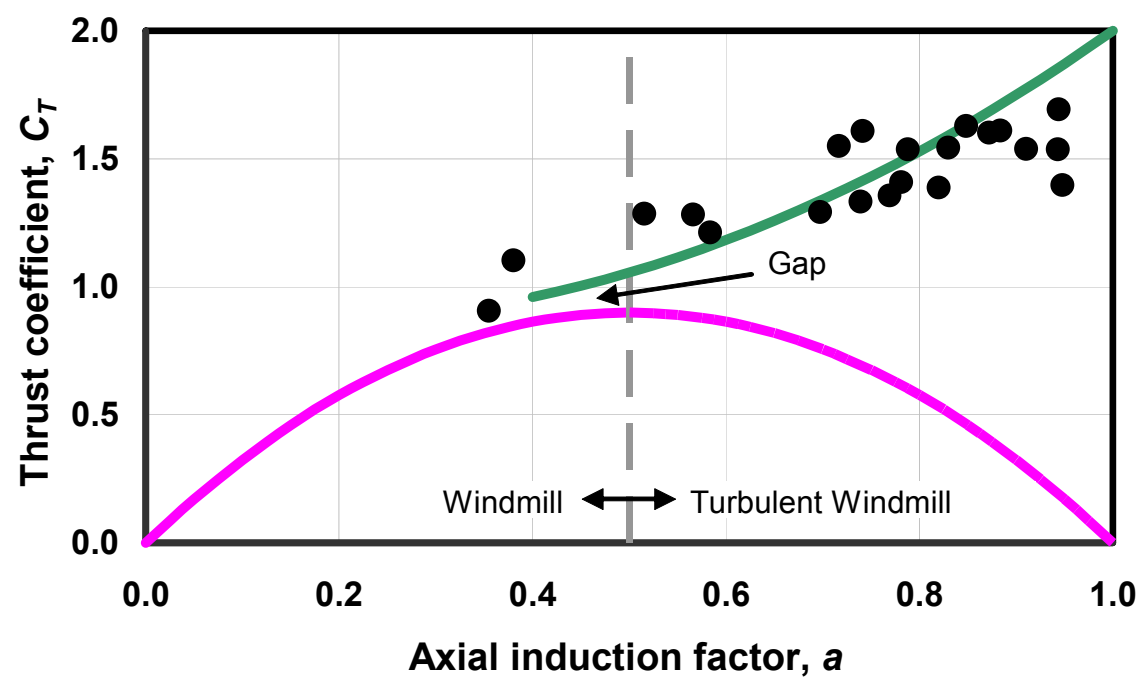

Figure 3. Classical $C_{T}-$ a curve with losses $(F=0.9)$ included and Glauert's empirical relationship 


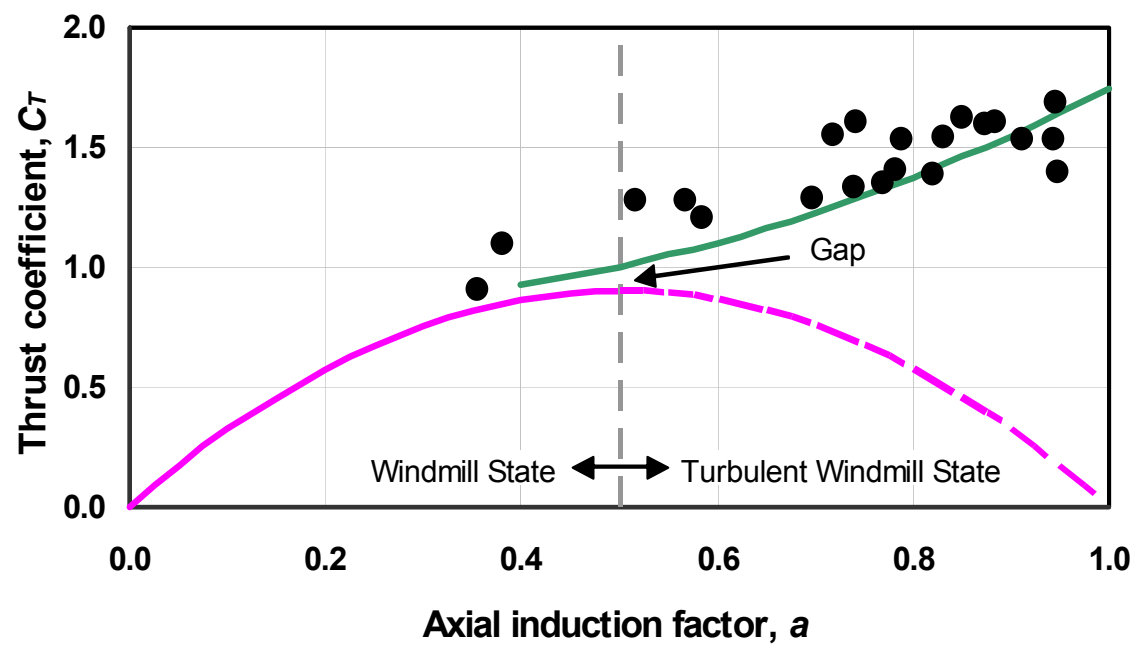

Figure 4. Classical $C_{T}-$ a curve and Glauert's empirical relationship when losses $(F=0.9)$ are included in both equations

A general quadratic equation for thrust coefficient is

$$
C_{T}=b_{0}+b_{1} a+b_{2} a^{2}
$$

where $b_{0}, b_{1}$, and $b_{2}$, must be selected to satisfy the conditions stated above. The slope of this equation is

$$
\frac{d C_{T}}{d a}=b_{1}+2 b_{2} a
$$

At an induction factor of 0.4, Equations 7 and 8 become

$$
C_{T}=b_{0}+0.4 b_{1}+0.16 b_{2}
$$

and

$$
\frac{d C_{T}}{d a}=b_{1}+0.8 b_{2}
$$

When we equate Equations 5 and 9, we get

$$
b_{0}+0.4 b_{1}+0.16 b_{2}=0.96 F \text {. }
$$

Equating Equations 6 and 10 yields

$$
b_{1}+0.8 b_{2}=0.8 F \text {. }
$$

At an induction factor of 1 , we want our quadratic to be equal to 2 , so 


$$
C_{T}=b_{0}+b_{1}+b_{2}=2 .
$$

If we subtract Equation 11 from Equation 13, we get

$$
0.6 b_{1}+0.84 b_{2}=2-0.96 F \text {. }
$$

Next, if we subtract $0.6^{*}$ Equation 12 from Equation 14 and solve for $b_{2}$ we get

$$
b_{2}=\frac{50}{9}-4 F \text {. }
$$

Solving Equation 12 for $b_{1}$ yields

$$
b_{1}=\frac{4}{5} F-b_{2}=4 F-\frac{40}{9} \text {, }
$$

And solving Equation 13 for $b_{0}$ yields

$$
b_{0}=2-b_{1}-b_{2}=\frac{8}{9} \text {. }
$$

We now have an equation that produces a curve that just touches the classical momentum equation at $a=0.4$ and goes through 2 at $a=1$ (see Figure 5).

$$
C_{T}=\frac{8}{9}+\left(4 F-\frac{40}{9}\right) a+\left(\frac{50}{9}-4 F\right) a^{2} .
$$

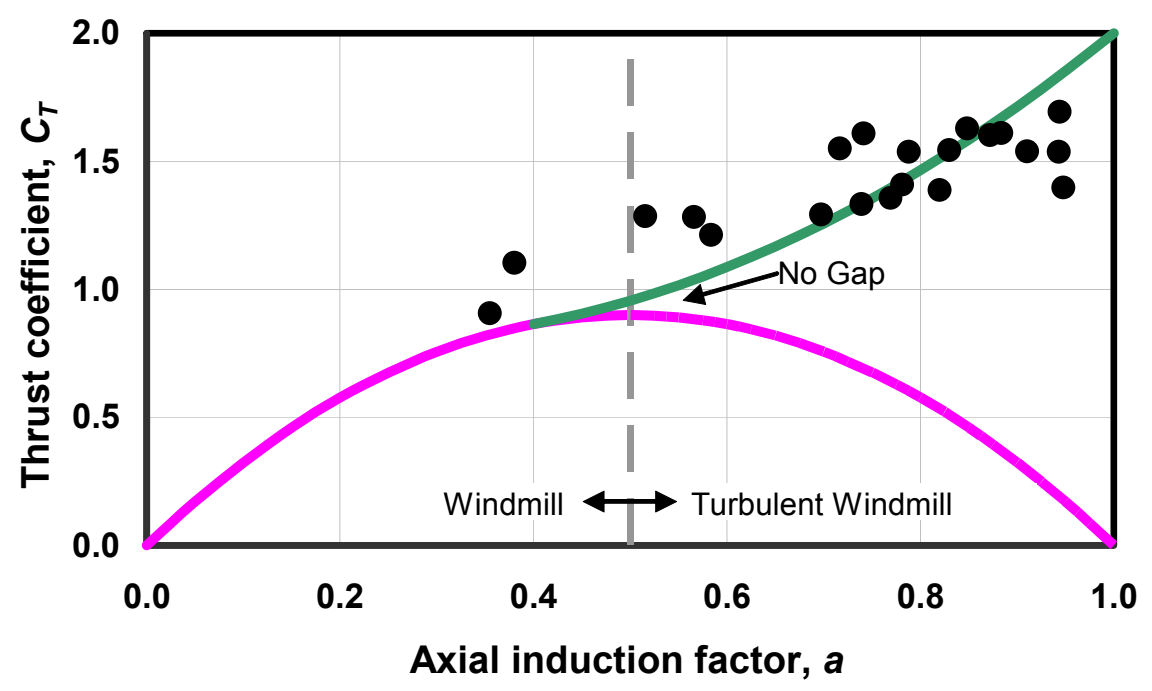

Figure 5. Classical $C_{T}-a$ curve and the newly derived empirical relationship when losses $(F=0.9)$ are included in both equations 


\section{Conclusions}

We have shown that previous relationships between the thrust coefficient and the induction factor in the turbulent windmill state have produced numerical discontinuities in the induction iteration with tip or hub losses. We derived a new equation that solves the discontinuity problem and provides a reasonable approximation to the experimental data. Although it is not a perfect fit to the data, it is probably as good as the original Glauert equation. This is the best-known method to compute the induction in the turbulent windmill state. However, it does not account for the spread in the data, which is a problem that needs further investigation.

\section{References}

Burton, T.; Sharpe, D.; Jenkins, N.; Bossanyi, E.. (2001). Wind Energy Handbook. West Sussex, England: John Wiley \& Sons, Ltd.; pp. 66-68.

Eggleston, D.M.; Stoddard, F.S. (1987). Wind Turbine Engineering Design. New York, NY: Van Nostrand Reinhold; pp. 30-35, 58.

Glauert, H. (1926). The Analysis of Experimental Results in the Windmill Brake and Vortex Ring States of an Airscrew, Rept. 1026. Aeronautical Research Committee Reports and Memoranda, London: Her Majesty's Stationery Office.

Lock, C.N.H.; Batemen, H.; Townsend, H.C.H. (1926). An Extension of the Vortex Theory of Airscrews with Applications to Airscrews of Small Pitch, Including Experimental Results. No. 1014. Aeronautical Research Committee Reports and Memoranda, London: Her Majesty's Stationery Office.

Manwell, J.F.; McGowan, J.G.; Rogers, A.L. (2002). Wind Energy Explained. West Sussex, England: John Wiley \& Sons, Ltd.; pp. 120-121.

Wilson, R.E. (1994). “Aerodynamic Behavior of Wind Turbines,” Chapter 5. Spera, D.A., ed. Wind Turbine Technology. New York, NY: The American Society of Mechanical Engineers; pp. 231-232. 


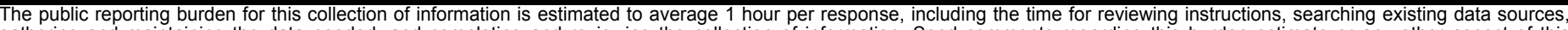

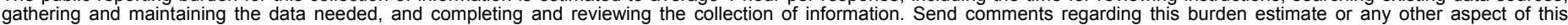

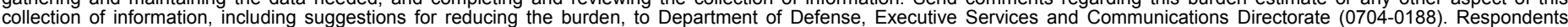

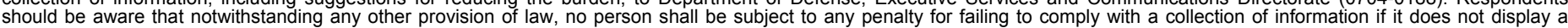

should be aware that notwithstanding

PLEASE DO NOT RETURN YOUR FORM TO THE ABOVE ORGANIZATION.

\section{REPORT DATE (DD-MM-YYYY) August 2005}

4. TITLE AND SUBTITLE

A New Empirical Relationship between Thrust Coefficient and Induction Factor for the Turbulent Windmill State
3. DATES COVERED (From - To)

5a. CONTRACT NUMBER

DE-AC36-99-G010337

5b. GRANT NUMBER

5c. PROGRAM ELEMENT NUMBER

5d. PROJECT NUMBER

NREL/TP-500-36834

5e. TASK NUMBER

WER43305

5f. WORK UNIT NUMBER
7. PERFORMING ORGANIZATION NAME(S) AND ADDRESS(ES)

National Renewable Energy Laboratory

1617 Cole Blvd.

Golden, CO 80401-3393

9. SPONSORING/MONITORING AGENCY NAME(S) AND ADDRESS(ES)
8. PERFORMING ORGANIZATION REPORT NUMBER

NREL/TP-500-36834
10. SPONSOR/MONITOR'S ACRONYM(S) NREL

11. SPONSORING/MONITORING AGENCY REPORT NUMBER

12. DISTRIBUTION AVAILABILITY STATEMENT

National Technical Information Service

U.S. Department of Commerce

5285 Port Royal Road

Springfield, VA 22161

13. SUPPLEMENTARY NOTES

14. ABSTRACT (Maximum 200 Words)

Classical momentum theory shows a relationship between the thrust coefficient and the axial induction factor. Glauert plotted some experimental results against this parabolic relationship and found very poor agreement for operation in the turbulent windmill state. He proposed a new empirical relationship to fit the experimental data. Unfortunately, the new empirical curve does not account for tip or hub losses. Others have proposed that one simply multiply the axial induction factor but the loss factor to correct the curve, but this still leaves a mathematical no man's land between the classical curve and the modified version of Glauert's empirical curve. This paper derives a new curve that accounts for tip and hub losses and eliminates the discontinuity.

15. SUBJECT TERMS

momentum theory; Glauert; induction; wind turbine; turbulent windmill state

\begin{tabular}{|c|c|c|c|c|c|}
\hline 16. SECURITY & CLASSIFICATI & N OF: & 17. LIMITATION & 18. NUMBER & 19a. NAME OF RESPONSIBLE PERSON \\
\hline a. REPORT & b. ABSTRACT & c. THIS PAGE & OF ABS IRACI & & \\
\hline Unclassitıed & Unclassified & Unclassified & & & 19b. TELEPHONE NUMBER (Include area code) \\
\hline
\end{tabular}

